\title{
Effect of a financial incentive on the acceptance of a smoking cessation programme with service charge: a cluster-controlled trial
}

\author{
KS Wong *, SN Fu, KL Cheung, MC Dao, WM Sy
}

This article was published on $4 \mathrm{Apr}$ 2018 at www.hkmj.org.

\section{A B S T R A C T}

Introduction: Frontline health care professionals in Hong Kong may encounter high refusal rates for the Hospital Authority's Smoking Counselling and Cessation Programme (SCCP) when smokers know it is subject to a service charge. We compared SCCP booking and attendance rates among smokers with or without a financial incentive.

Methods: In this multicentre non-randomised cluster-controlled trial, adult smokers who attended one of six general out-patient clinics between November 2015 and April 2016 were invited to join an SCCP. Attendees in the three intervention-group centres but not the three control-group centres received a supermarket coupon to offset the service charge.

Results: A total of 173 smokers aged 18 years or older (92 in the intervention group and 81 in the control group) were recruited into the study. In the intervention group, 47 smokers (51\%) agreed via a questionnaire that they would join the SCCP, compared with only 23 smokers in the control group $(28 \%)$. The booking rates were $83 \%(n=39)$ in the intervention group and $83 \%(n=19)$ in the control group. Among those who had booked a place, 19 (49\%) intervention-group participants and 11
(58\%) control-group participants attended an SCCP session. Multivariable logistic regression revealed that offering a coupon was associated with agreeing to join an SCCP (odds ratio $=4.963,95 \%$ confidence interval $=2.173-11.334 ; \mathrm{P}<0.001)$ and booking an SCCP place (odds ratio $=4.244,95 \%$ confidence interval=1.838-9.799; $\mathrm{P}<0.001)$.

Conclusion: Provision of a financial incentive was positively associated with agreement to join an SCCP and booking an SCCP place. Budget holders should consider providing the SCCP free of charge to increase smokers' access to the service.

\section{Hong Kong Med J 2018;24:128-36}

DOI: 10.12809/hkmj176960

\author{
${ }^{1}$ KS Wong *, MB, BS \\ ${ }^{2} \mathrm{SN} F u, M B, B S, M F M$ \\ ${ }^{2} \mathrm{KL}$ Cheung, $\mathrm{MB}, \mathrm{ChB}$ \\ ${ }^{2} \mathrm{MC}$ Dao, MB, BS \\ ${ }^{2}$ WM Sy, MB, BS
}

1 Family Medicine and General Out-patient Clinics, Kowloon Central Cluster, Hospital Authority, Hong Kong

2 Family Medicine \& Primary Health Care, Kowloon West Cluster, Hospital Authority, Hong Kong

* Corresponding author: wks638@ha.org.hk

New knowledge added by this study

- This study reveals that provision of a financial incentive to offset the service charge of the Smoking Counselling and Cessation Programme in Hong Kong might increase the proportion of smokers who agree to join the programme and make an appointment.

Implications for clinical practice or policy

- Budget holders should consider providing a free Smoking Counselling and Cessation Programme to increase smokers' access to the service.

\section{Introduction}

There is no doubt that smoking is a serious hazard to health. ${ }^{1-3}$ One in two smokers will be killed by smoking; if one can help two smokers to quit, at least one life will be saved. ${ }^{4}$ Individual counselling by trained therapists can assist smokers to quit. ${ }^{5-7}$ The counselling usually involves review of the participant's smoking history and motivation to quit, provision of problem-solving strategies to deal with high-risk situations, and encouragement. Smokers who receive individual counselling are 39\% more likely to cease smoking in the long term than smokers who receive minimal behavioural intervention. ${ }^{5}$ Another method to increase the smoking cessation rate is nicotine replacement therapy (NRT). Such therapy (eg, gum, transdermal patch, and lozenges) is cost-effective in smoking cessation and increases the rate of quitting by $50 \%$ to $70 \%{ }^{8-11}$ Combining counselling and pharmacotherapy has been shown to further increase smoking cessation success rates by more than $80 \%$ when compared with minimal intervention or usual care. ${ }^{12}$ If a smoker quits smoking in the absence of external assistance, there is only a $3 \%$ to $5 \%$ chance of sustained abstinence at 6 to 12 months. ${ }^{13}$ 
In Hong Kong, the Smoking Counselling and Cessation Programme (SCCP) consists of individual counselling and provision of NRT and is available from the Hospital Authority; similar services are also provided by the Department of Health and the Tung Wah Group of Hospitals. ${ }^{14}$ The Hospital Authority operates 58 smoking cessation and counselling centres. Despite this available support, only about $19 \%$ of current smokers in Hong Kong have tried a smoking cessation service. ${ }^{15}$ In contrast, the prevalence of assisted quit attempts was $59.4 \%$ in Australia in 2008-2009 and 53.6\% in the United Kingdom in $2010 .{ }^{16}$

The SCCP in Hong Kong is offered as part of chronic care, and general out-patient clinics (GOPCs) provide a good opportunity for health care professionals to refer smokers to an SCCP. Frontline GOPC health care professionals in Hong Kong may encounter high refusal rates of SCCP service when smokers know they must pay a service charge. Currently, smoking cessation and counselling centres SCCC charge HK\$50 [ US\$6.40] (HK\$45 [ US\$5.80] at the time of this study) for an initial face-to-face consultation, unless the client is exempt (eg, those receiving the Comprehensive Social Security Allowance or civil servants). There is no extra charge for NRT.

A review article in the Cochrane Library by Reda et $\mathrm{al}^{17}$ proposed that if all costs to smokers are covered, the proportion of smokers who attempt to quit, use smoking cessation treatments, and succeed in quitting will significantly increase compared with provision of no financial support. Reda et $\mathrm{al}^{17}$ also suggested that even though the absolute differences in quitting were small when an intervention group was compared with a control group (total events: 134 of 1409 vs 75 of 1351 , respectively), the costs per person successfully quitting were low or moderate (US\$119 to US\$6450). However, all the studies included in that review were conducted in western countries, where the health care financing systems may differ from that of Hong Kong. In this study, we aimed to determine whether the booking and attendance rates at a smoking cessation service (SCCP) in a primary care setting could be increased if the patient received a financial incentive, as payment-in-kind, to offset the service fee.

\section{Methods}

\section{Study design and population}

This was a multicentre non-randomised clustercontrolled trial involving six GOPCs of the Hong Kong Hospital Authority's Kowloon West Cluster and conducted from November 2015 to April 2016. The study protocol was approved by the Hospital Authority Kowloon West Cluster Research Ethics Committee (Ref No. KW/EX-15-169(91-

\section{財政誘因對收費戒煙計劃接受程度的影響： 集群對照試驗}

\author{
黃桂嫦、傅秀雅、張國良、陶敏之、施詠雯
}

引言: 前線醫護人員在推行醫院管理局戒煙輔導服務計劃（簡稱 SCCP）時困難重重, 尤其當知道須收取服務費用時, 吸煙者的參與 意欲便更低。本研究旨在檢視財政誘因對吸煙者預約和出席SCCP活 動的影響。

方法：在這項多中心非隨機集群對照試驗中, 於 2015 年11月至2016 年 4 月期間前往本地六間普通科門診診所的成年吸煙者受邀參與 $\mathrm{SCCP}$ 。其中三間為干預組, 參與者會獲得超市禮券以抵消服務費 用。另外三間為對照組

結果：研究共納入 173 名 18 歲或以上吸煙者（干預組 92 人, 對照組 81 人) 。在干預組中, 47 名吸煙者 $(51 \%)$ 透過調查問卷同意參加 SCCP , 而對照組同意參加的只有 23 名 (28\%)。干預組SCCP預約 率為 $83 \%(n=39)$, 對照組則為 $83 \%(n=19)$ 。在已預約的參與者 中, 干預組有 19 名 (49\%) 和控制組有 11 名 $(58 \%)$ 出席SCCP活 動。多因素䍜輯迴歸分析顯示, 提供禮券與同意參加SCCP (比值比 $=4.963,95 \%$ 置信區間 $=2.173-11.334 ; \mathrm{P}<0.001)$ 和預約 SCCP活動 （比值比 $=4.244 ， 95 \%$ 置信區間=1.838-9.799；P<0.001）相關。

結論：提供財政誘因與同意參加和預約 SCCP活動呈正相關。預算持 有者或應考慮免收SCCP服務費用，增加吸煙者獲得服務的機會。

08)). Non-random cluster sampling was used to choose participating clinics and assign them to study group, in order to avoid contamination of participants between the intervention and control groups. Three clinics (Ha Kwai Chung GOPC, West Kowloon GOPC, and Tsing Yi Cheung Hong GOPC) were assigned to the intervention group and three (Cheung Sha Wan GOPC, Li Po Chun GOPC, and South Kwai Chung GOPC) to the control group. A standard regular SCCP was available at all six clinics. The SCCP counsellors were trained nurses or pharmacists and all underwent the same smoking cessation counselling training provided by the Hospital Authority Head Office. The GOPC staff and SCCP counsellors were not involved in clinic selection or assignment.

The study centres were six of the 73 governmentfunded primary care GOPCs, and the majority of their patients were from a lower socio-economic class or older patients with chronic illnesses. The patient profiles from the six GOPCs shared a similar socio-demographic background and disease profile. There was no pre-study SCCP booking rate available, but the total number of smokers recruited from the three control clinics into the SCCP during the study period was similar to the number of SCCP referrals made by the three clinics during an equivalent period in the previous year (November 2014 to April 2015). The attendance rate for booked SCCP appointments was logged by the clinic computer system and was 
$50 \%$ to $60 \%$ among all six clinics.

Convenience sampling was used to recruit current smokers at the time of recruitment, ${ }^{15}$ who were identified during a doctor's consultation or nurse's assessment during the daytime. Information about this study and possible recruitment of patients for SCCP referral was given to doctors and nurses before the start of the study. After valid consent had been obtained, participants were invited to complete a questionnaire to provide background information, smoking status, and decision to join an SCCP. Assistance was given with the questionnaire if required. The questionnaires distributed to the control group (online supplementary Appendix 1) and the intervention group (online supplementary Appendix 2) stated the usual SCCP service charge of $\mathrm{HK} \$ 45$. The intervention group's questionnaire additionally stated that a HK\$50 supermarket coupon would be given to SCCP attendees. Those who agreed to participate in the SCCP were directed to make an appointment via the registration counter.

The SCCP counsellors in the intervention group were briefed by the authors about the process of issuing a supermarket coupon as payment in-kind to SCCP attendees. The SCCP session was carried out as usual, regardless of study group. In clinics in the intervention group, the supermarket coupon was given to SCCP participants after payment of the service charge.

\section{Inclusion and exclusion criteria}

Current smokers who were aged 18 years or older were eligible for the study. Participants were excluded if (1) the SCCP service charge was waivedfor example, if they were a Comprehensive Social Security Allowance recipient or a civil servant; (2) they were as mentally incapacitated and unable to give consent; or (3) they were pregnant, as there was concern that NRT may increase the risk of congenital respiratory anomalies. ${ }^{18}$

\section{Recruitment questionnaire}

A structured questionnaire in traditional Chinese script (online supplementary Appendices 1 and 2) was used to collect the following information:

(1) Age, sex, mean personal monthly income, and whether the participant thought the clinic was a convenient place to go;

(2) Smoking history: age when starting smoking, number of years of smoking, the mean number of cigarettes consumed per day (CPD), and time to the first cigarette of the day (TTFC) after waking. The nicotine dependence level was measured by CPD and TTFC, which have been shown to be independent predictors of quitting outcome. ${ }^{19}$ A categorical scoring method has been deemed adequate for many purposes ${ }^{19}$ and was adopted in this study (CPD categories of $0-10,11-20,21-30$, and $\geq 31$; TTFC categories of $\leq 5,6-30,31-60$, and $\geq 61$ minutes);

(3) Rating (range, 0-10) of perceived importance of, readiness for, and confidence in smoking cessation, which have been reported to be associated with smoking behavioural change ${ }^{20}$;

(4) If the smoker agrees to join the SCCP.

The questionnaire comprised 14 questions. The relevance and content validity of the questionnaire were reviewed by senior doctors. It was also pilottested in 10 smokers for face validity.

\section{Outcome measures}

The rates of agreement between questionnaire response rate for intention to book an SCCP appointment, actual SCCP booking rate via the registration counter, and SCCP attendance rate were compared between the intervention and control groups. Defaulters or participants who rescheduled their SCCP sessions outside the study period were treated as non-attendees. Smokers who joined the SCCP were followed up by telephone by smokingcessation counsellors on the seventh day after the first consultation to enquire whether they had quit smoking and were not smoking on the day of the call. This is a standard outcome measure of the SCCP used by the Hospital Authority.

\section{Sample-size calculation}

The sample size was based on the annual quit rate of smokers in 2014 (of 9.6\%) for all GOPCs under the Hospital Authority, according to an internal report. In a Cochrane review of health care financing systems to increase the uptake of tobacco-dependence treatment, full financial interventions (ie, covering all costs) directed at smokers could increase abstinence rate at 6 months or longer by 2.45 times that of smokers with no financial intervention (risk ratio $=2.45$, $95 \%$ confidence interval $[\mathrm{CI}]=1.17-5.12, I^{2}=59 \%, 4$ studies). ${ }^{17}$ In a study by Kaper et al, ${ }^{21}$ the adjusted odds ratio for abstinence after reimbursement was 2 to 4 times that after no reimbursement. It was thus estimated that offering reimbursement to attend an SCCP would triple the programme attendance rate. Using the formula established by Casagrande et al, ${ }^{22}$ 65 participants were required in each group in order to obtain an alpha of 0.05 and $80 \%$ power. Assuming a $20 \%$ attrition rate, 80 participants were required in each group.

\section{Statistical analysis}

Data analysis was performed with SPSS (Windows version 20.0; IBM Corp, Armonk [NY], United States). The level of significance was set at $5 \%$. Data of the intervention and the control groups were summarised by descriptive statistics. Categorical 
variables were expressed as percentages and compared between the two groups by Pearson's chi-square test or Fisher's exact test. Continuous variables were tested for normality with ShapiroWilk's test. Normally distributed variables were expressed as means with standard deviations and compared with Student's $t$ test. Variables that were non-normally distributed were presented as medians with interquartile ranges and compared with the Mann-Whitney $U$ test. The association between participants' characteristics, reimbursement, and outcomes were studied by univariate logistic regression analysis and multivariable logistic regression analysis using backward elimination, yielding crude odds ratios (ORs) and 95\% CIs. Intention-to-treat analysis was used, and missing data were handled by listwise deletion.

\section{Results}

\section{Participant recruitment}

In the control group clinics, a total of 90 smokers were approached, of whom two refused to participate in the study (response rate, 98\%). Seven were excluded, as their questionnaires were incomplete or their SCCP fee would have been waived. In the intervention group clinics, a total of 151 smokers were approached, of whom 28 refused to participate in the study (response rate, $81 \%$ ). Thirty-one were excluded, as their questionnaires were incomplete or their SCCP fee would have been waived. There were 81 and 92 smokers (total, 173) recruited into the control group and intervention group, respectively.

\section{Study population characteristics}

There was no statistical difference between the two groups in terms of sex; age when starting smoking; mean cigaretteconsumption perday;TTFC;perceived importance of, readiness for, and confidence in smoking cessation; perceived convenience of clinic location; mean monthly income; and waiting time for SCCP (Table 1). More than $90 \%$ of participants were male, had a mean monthly income of $<\mathrm{HK} \$ 30000$, and believed that the SCCP clinic was conveniently located. The median age at starting smoking was 18 years. Nearly half of the smokers were medium smokers, consuming 11 to $20 \mathrm{CPD}$. The TTFC was less than 31 minutes for more than $67 \%$ of smokers. The rating (from 0 to 10) of perceived importance of, readiness for, and confidence in quitting was 5 , 3 , and 4, respectively. The waiting time for an SCCP appointment was longer than 1 month for over $65 \%$ of participants.

The age and the duration of smoking of the participants were statistically different between the two groups. The mean age of the control group was 4 years older than that of the intervention group ( 61.6 vs 57.6 years; $\mathrm{P}=0.048$ ). The mean duration of smoking in the control group was 4 years longer than that in the intervention group (41.4 vs 36.9 years; $\mathrm{P}=0.047)$.

\section{Outcomes}

The Figure summarises the SCCP booking and attendance rates. In the intervention group, 47 smokers $(51 \%)$ indicated on the questionnaire their agreement to join an SCCP, whereas only 23 smokers (28\%) did so in the control group. Of those who agreed in principle, $39(83 \%)$ in the intervention group made a booking compared with only 19 (83\%) in the control group. For those who had booked an SCCP place, $19(49 \%)$ and $11(58 \%)$ attended the sessions in the intervention and control group, respectively. Three smokers (16\%) in the intervention group were lost to follow-up and were counted as non-quitters. Four smokers $(21 \%)$ in the intervention group and two $(18 \%)$ in the control group quit successfully by the seventh day.

Univariate logistic regression analysis (Table 2) revealed that the financial intervention was associated with a higher rate of agreeing to join an SCCP $(\mathrm{OR}=2.634,95 \% \mathrm{CI}=1.399-4.959 ; \mathrm{P}=0.003)$ and booking of an SCCP appointment $(\mathrm{OR}=2.401$, 95\% $\mathrm{CI}=1.242-4.644 ; \quad \mathrm{P}=0.009)$, but not with attending an SCCP. Factors that were associated with a higher rate of agreeing to join, booking, and attending an SCCP session were consuming 11 to 20 CPD and higher ratings of perceived readiness for and confidence in smoking cessation. Other factors that were associated with a higher rate of agreeing to join and booking an SCCP session were $\leq 5$ minutes for TTFC and higher rating of perceived importance of smoking cessation.

Multivariable logistic regression analysis (Table 3) revealed that the financial intervention was associated with a higher rate of agreeing to join an SCCP $(\mathrm{OR}=4.963,95 \% \mathrm{CI}=2.173-11.334 ; \mathrm{P}<0.001)$ and of booking an SCCP appointment $(\mathrm{OR}=4.244$, 95\% $\mathrm{CI}=1.838-9.799 ; \mathrm{P}<0.001)$, but not with actual attendance. Higher ratings of smokers' perceived readiness for smoking cessation was associated with a higher rate of agreeing to join, booking, and attending an SCCP session. Other factors that were associated with a higher rate of agreeing to join an SCCP and making a booking were $\leq 5$ minutes and 6-30 minutes of TTFC and a mean monthly income of HK\$10000-29999. Mean cigarette consumption of 11 to $20 \mathrm{CPD}$ was associated with a higher rate of attendance at an SCCP.

\section{Discussion}

In Hong Kong, there are so far no published data on the effect of reimbursement on booking and attendance rates for smoking cessation programmes. Overseas studies have evaluated the effect of 
TABLE I. Baseline characteristics of participants*

\begin{tabular}{|c|c|c|c|}
\hline & Control group $(n=81)$ & Intervention group ( $\mathrm{n}=92)$ & Total $(n=173)$ \\
\hline \multicolumn{4}{|l|}{ Sex } \\
\hline Female & $5(6.2)$ & $11(12.0)$ & $16(9.2)$ \\
\hline Male & $76(93.8)$ & $81(88.0)$ & $157(90.8)$ \\
\hline Age, mean (SD), y† & $61.6(12.3)$ & $57.6(14.1)$ & $59.5(13.4)$ \\
\hline Age at starting smoking, median (IQR), y & $18(15-22.5)$ & $18(16-22)$ & $18(16-22)$ \\
\hline Duration of smoking, mean (SD), y† & $41.4(14.0)$ & $36.9(15.4)$ & $39.0(14.9)$ \\
\hline \multicolumn{4}{|l|}{ Cigarettes consumed per day } \\
\hline $0-10$ & $32(39.5)$ & $27(29.3)$ & $59(34.1)$ \\
\hline $11-20$ & 34 (42.0) & $50(54.3)$ & $84(48.6)$ \\
\hline $21-30$ & $10(12.3)$ & $10(10.9)$ & $20(11.6)$ \\
\hline$\geq 31$ & $5(6.2)$ & $5(5.4)$ & $10(5.8)$ \\
\hline \multicolumn{4}{|l|}{ Time to first cigarette, $\min$} \\
\hline$\geq 61$ & $14(17.3)$ & $17(18.5)$ & $31(17.9)$ \\
\hline $31-60$ & $11(13.6)$ & $14(15.2)$ & $25(14.5)$ \\
\hline $6-30$ & $28(34.6)$ & $30(32.6)$ & $58(33.5)$ \\
\hline$\leq 5$ & $28(34.6)$ & $31(33.7)$ & $59(34.1)$ \\
\hline Importance of quitting, median (IQR) & $5(4.5-7.5)$ & $5.5(4-7.75)$ & $5(4-7.5)$ \\
\hline Readiness for quitting, median (IQR) & $3(0-5.5)$ & $3(0-6)$ & $3(0-6)$ \\
\hline Confidence in quitting, median (IQR) & $4(0-7)$ & $4(0-5)$ & $4(0-6)$ \\
\hline \multicolumn{4}{|l|}{ Location of SCCP clinic } \\
\hline Inconvenient & $4(4.9)$ & $7(7.6)$ & $11(6.4)$ \\
\hline Convenient & $77(95.1)$ & $85(92.4)$ & $162(93.6)$ \\
\hline \multicolumn{4}{|l|}{ Mean monthly income, HK\$ } \\
\hline Unemployed & $35(43.2)$ & $32(34.8)$ & $67(38.7)$ \\
\hline $1-9999$ & $15(18.5)$ & $24(26.1)$ & $39(22.5)$ \\
\hline $10000-29999$ & $29(35.8)$ & $29(31.5)$ & $58(33.5)$ \\
\hline $30000-49999$ & $2(2.5)$ & $7(7.6)$ & $9(5.2)$ \\
\hline \multicolumn{4}{|l|}{ Waiting time for SCCP appointment } \\
\hline Same day as recruitment day & $3(15.8)$ & $4(10.3)$ & $7(12.1)$ \\
\hline Within 1 month & $4(21.1)$ & $9(23.1)$ & $13(22.4)$ \\
\hline$\geq 1$ Month & $12(63.2)$ & $26(66.7)$ & 38 (65.5) \\
\hline
\end{tabular}

Abbreviations: $\mathrm{IQR}=$ interquartile range; $\mathrm{SCCP}=$ Smoking Cessation and Counselling Programme; $\mathrm{SD}=$ standard deviation

* Data are shown as No. (\%), unless otherwise noted

$+\mathrm{P}<0.05$

‡ For 19 participants in the control group and 39 participants in the intervention group

reimbursement on quitting attempts and abstinence rates, but not attendance at smoking cessation services. This study provides some insights into this area.

The participants in the control and intervention group were comparable except for mean age (62 vs 58 years) and duration of smoking (41 vs 37 years). Simply offsetting the HK\$45 SCCP fee with a HK\$50 supermarket coupon significantly increased smokers' willingness to join or actually book an SCCP session $(\mathrm{OR}=4.963$ and 4.244, respectively) [Table 3]. This finding suggests that a financial intervention may make more smokers consider joining an SCCP. With further counselling and NRT in the SCCP, the road to successful smoking cessation may be shortened.

The lack of an association between attendance rate and reimbursement might be explained by the waiting time for SCCP (Table 4). Owing to human resource constraints, more than $65 \%$ of SCCP appointments had to be scheduled for over a month after participant recruitment. The mean waiting time was 37 days for the intervention group and 33 days 


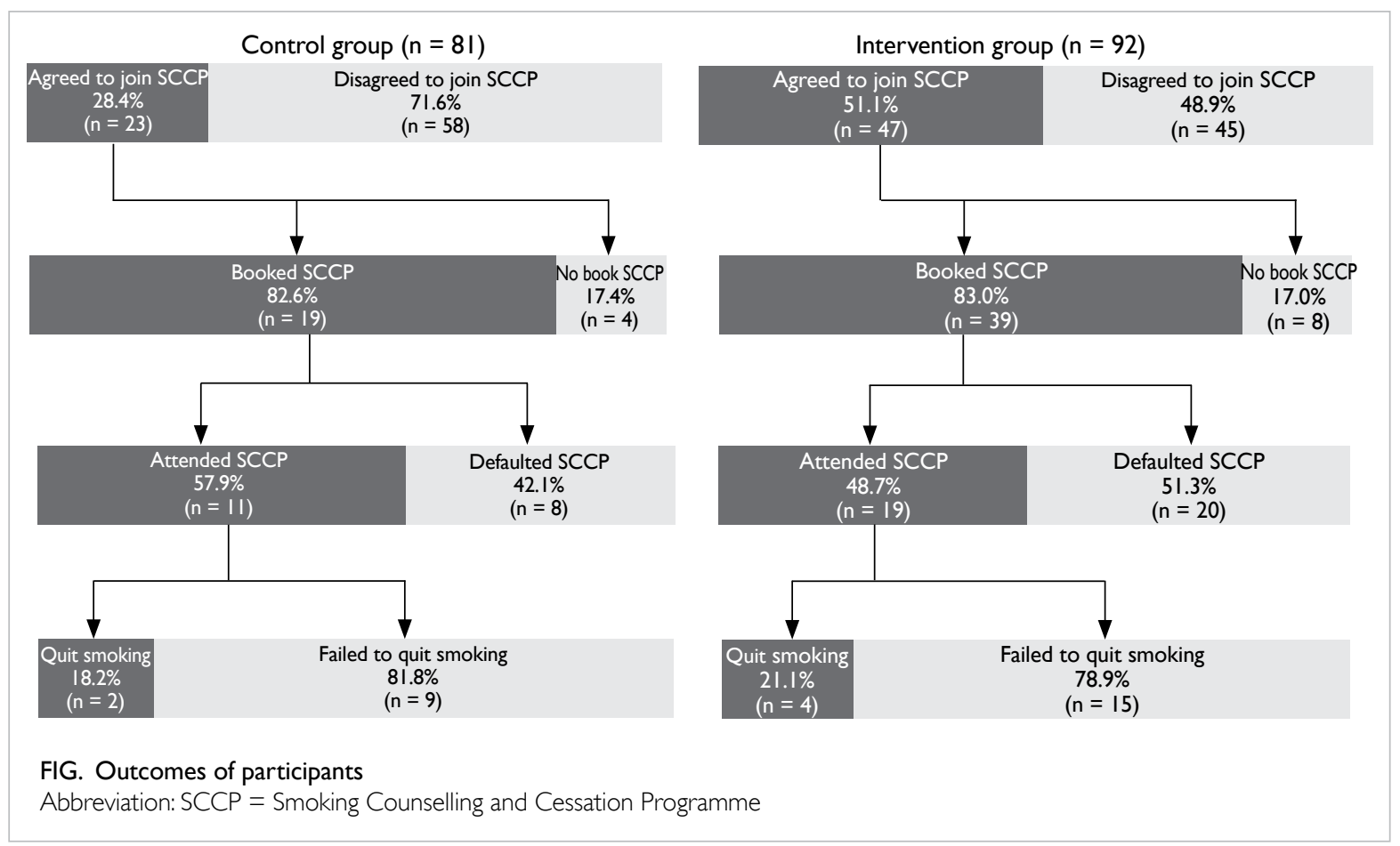

for the control group. The attendance rate dropped from $69 \%$ to $37 \%$ when the appointment date was over a month away. This finding was in keeping with an overseas study that reported long waiting times as one of the reasons for non-attendance at a quitting programme. ${ }^{23}$ Future local studies might involve exploring the reasons for programme nonattendance and would help service providers to improve the SCCP and help more smokers quit.

In a local evaluative study of the integrated smoking cessation services of the Tung Wah Group of Hospitals in 2011, the majority of clients (52.6\%) consumed 11-20 CPD. ${ }^{24}$ More than half (54.4\%) of those who attended smoking cessation clinics of the Tung Wah Group of Hospitals had a high dependency on nicotine. ${ }^{24}$ In agreement, our study found that smokers consuming 11-20 CPD were significantly more likely to attend an SCCP than lighter smokers $(\mathrm{OR}=4.443)$. We also found that smokers with shorter TTFC were significantly more likely to agree to join or book an SCCP session (TTFC $\leq 5$ minutes: $\mathrm{OR}=9.788$ and 9.871, respectively; TTFC 6-30 minutes: $\mathrm{OR}=3.954$, and $\mathrm{OR}=4.916$, respectively).

Individuals in the quitting preparation stage display the highest motivation-ruler ratings. ${ }^{20} \mathrm{In}$ our study, smokers with a higher rating of readiness were more likely to have a higher rate of deciding to join, book, or attend an SCCP (Table 3). This finding indicates that smokers who were recruited to join an SCCP were prepared to quit. Concerns that offering a financial incentive might invite smokers who had no genuine intention to quit are unfounded. Offering help to smokers for quitting was one of the MPOWER (Monitor, Protect, Offer, Warn, Enforce, and Raise) measures described by the World Health Organization to combat the global tobacco epidemic. ${ }^{25}$ Hong Kong is fortunate to have a well-established smoking cessation programme, so the service deserves to be fully used.

\section{Limitations}

The smokers recruited into this study were a convenience sample of attendees at GOPCs, so their characteristics would differ from those of the general smoking population in Hong Kong ${ }^{15}$ in terms of a larger proportion of males ( $90.8 \%$ vs $83.9 \%)$, higher daily cigarette consumption $(48.6 \%$ consuming 11-20 CPD vs $56.0 \%$ consuming 1-10 CPD), and larger proportion of economically inactive smokers (38.7\% vs $21.0 \%)$. The results thus may not be generalised to the whole population of Hong Kong smokers. Furthermore, retirement and economic inactivity may influence smoking habits ${ }^{26}$ and act as confounders, but these were not controlled in the multivariable analyses.

The control and intervention groups were not very comparable: the control group was slightly older and had smoked for slightly longer. Estimation of the sample size was suboptimal, as the total numbers of eligible smokers during the recruitment period and the estimated increase in attendance rate by financial incentives were not available before the study. 
TABLE 2. Results of univariate logistic regression analysis of association between participants' characteristics, financial intervention, and outcomes

\begin{tabular}{|c|c|c|c|c|c|c|}
\hline & \multicolumn{2}{|c|}{ Agreed to join SCCP } & \multicolumn{2}{|c|}{ Booked SCCP appointment } & \multicolumn{2}{|c|}{ Attended SCCP } \\
\hline & OR $(95 \% \mathrm{Cl})$ & $P$ value & OR (95\% Cl) & $P$ value & OR (95\% Cl) & $P$ value \\
\hline Age & $0.979(0.956-1.002)$ & 0.067 & $0.986(0.963-1.009)$ & 0.233 & $0.996(0.967-1.025)$ & 0.778 \\
\hline \multicolumn{7}{|l|}{ Sex (female as ref) } \\
\hline Male & $0.494(0.175-1.396)$ & 0.183 & $0.467(0.166-1.317)$ & 0.150 & $0.900(0.240-3.376)$ & 0.876 \\
\hline Age at starting smoking, y & $1.002(0.951-1.056)$ & 0.942 & $1.006(0.953-1.063)$ & 0.819 & $0.996(0.930-1.067)$ & 0.909 \\
\hline Duration of smoking, $y$ & $0.982(0.962-1.003)$ & 0.093 & $0.990(0.969-1.012)$ & 0.365 & $0.999(0.973-1.026)$ & 0.942 \\
\hline \multicolumn{7}{|c|}{ No. of cigarettes consumed (0-10 as ref) } \\
\hline $11-20$ & $3.214(1.539-6.715)$ & 0.002 & $2.798(1.298-6.031)$ & 0.009 & $4.583(1.482-14.171)$ & 0.008 \\
\hline $21-30$ & $2.630(0.906-7.634)$ & 0.075 & $2.109(0.691-6.440)$ & 0.190 & $3.437(0.772-15.307)$ & 0.105 \\
\hline$\geq 31$ & $3.214(0.811-12.739)$ & 0.097 & $2.611(0.634-10.750)$ & 0.184 & $1.528(0.153-15.266)$ & 0.718 \\
\hline \multicolumn{7}{|c|}{ Time to first cigarette, $\min (\geq 61$ as ref) } \\
\hline $31-60$ & $1.929(0.597-6.232)$ & 0.272 & $2.022(0.554-7.387)$ & 0.287 & $4.579(0.835-25.106)$ & 0.080 \\
\hline $6-30$ & $2.420(0.898-6.519)$ & 0.080 & $2.951(0.986-8.837)$ & 0.053 & $2.663(0.538-13.185)$ & 0.230 \\
\hline$\leq 5$ & $3.547(1.325-9.493)$ & 0.012 & $3.824(1.289-11.344)$ & 0.016 & $4.098(0.861-19.492)$ & 0.076 \\
\hline \multicolumn{7}{|c|}{ Importance of quitting ( $0-4$ as ref) } \\
\hline 5 & $1.033(0.422-2.529)$ & 0.943 & $1.312(0.499-3.450)$ & 0.581 & $1.026(0.304-3.464)$ & 0.967 \\
\hline $6-10$ & $2.214(1.033-4.746)$ & 0.041 & $2.625(1.150-5.990)$ & 0.022 & $1.773(0.649-4.844)$ & 0.264 \\
\hline \multicolumn{7}{|c|}{ Readiness for quitting ( $0-4$ as ref) } \\
\hline 5 & $4.506(1.819-11.162)$ & 0.001 & $3.857(1.530-9.726)$ & 0.004 & $2.708(0.804-9.118)$ & 0.108 \\
\hline $6-10$ & $6.609(3.090-14.132)$ & $<0.001$ & $6.300(2.922-13.582)$ & $<0.001$ & $6.238(2.451-15.873)$ & $<0.001$ \\
\hline \multicolumn{7}{|c|}{ Confidence in quitting ( $0-4$ as ref) } \\
\hline 5 & $4.295(1.855-9.945)$ & 0.001 & $3.567(1.525-8.340)$ & 0.003 & $2.453(0.832-7.236)$ & 0.104 \\
\hline $6-10$ & $3.156(1.522-6.545)$ & 0.002 & $3.352(1.575-7.134)$ & 0.002 & $3.644(1.443-9.202)$ & 0.006 \\
\hline \multicolumn{7}{|c|}{ Location of clinic (inconvenient as ref) } \\
\hline Convenient & $1.203(0.339-4.275)$ & 0.775 & $0.875(0.245-3.119)$ & 0.837 & $2.180(0.268-17.708)$ & 0.466 \\
\hline \multicolumn{7}{|c|}{$\begin{array}{l}\text { Mean monthly income, HK\$ (unemployed } \\
\text { as ref) }\end{array}$} \\
\hline 1-9999 & $1.246(0.554-2.802)$ & 0.594 & $1.044(0.443-2.463)$ & 0.921 & $0.755(0.262-2.180)$ & 0.604 \\
\hline $10000-29999$ & $1.560(0.761-3.200)$ & 0.224 & $1.544(0.735-3.243)$ & 0.251 & $0.865(0.348-2.153)$ & 0.756 \\
\hline $30000-49999$ & $0.896(0.205-3.908)$ & 0.884 & $1.175(0.267-5.169)$ & 0.831 & $0.519(0.060-4.526)$ & 0.553 \\
\hline \multicolumn{7}{|c|}{ Financial intervention (no as ref) } \\
\hline Yes & 2.634 (1.399-4.959) & 0.003 & $2.401(1.242-4.644)$ & 0.009 & $1.656(0.736-3.730)$ & 0.223 \\
\hline
\end{tabular}

Abbreviations: $\mathrm{Cl}=$ confidence interval; $\mathrm{OR}=$ odds ratio; ref = reference; SCCP = Smoking Counselling and Cessation Programme

Sample-size estimation was based on abstinence rates from previous studies instead of attendance rates. The number of participants who actually attended $(19+11=30)$ may be too small to show any statistical difference between SCCP attendance rates because the difference was less than the three-fold increase for the sample-size calculation.

In addition, the SCCP service in some clinics was restricted to certain days or times of the week owing to availability of counsellors. Some smokers, especially those who were working, may not have been able to find a session at a convenient time. This situation could have affected the booking and attendance rate between different clinics. In one of the returned questionnaires in which the participant ticked the box "agree to join SCCP" but did not make a booking, there was a written remark in Chinese: "Time does not fit".

This study was non-randomised and the doctors and nurses were not blinded to the financial intervention, because of the difficulty of running a complex workflow with limited resources. We assumed all doctors and nurses tried their best to assist smokers to quit. The possibility that those in the intervention group were more passionate in persuading patients to quit smoking cannot be excluded. The assignment of participants to the intervention or control group was not random 
TABLE 3. Results of multivariable logistic regression analysis of association between participants' characteristics, financial intervention, and outcomes*

\begin{tabular}{|c|c|c|c|c|c|c|}
\hline & \multicolumn{2}{|c|}{ Agreed to join SCCP } & \multicolumn{2}{|c|}{ Booked SCCP appointment } & \multicolumn{2}{|c|}{ Attended SCCP } \\
\hline & OR $(95 \% \mathrm{Cl})$ & $P$ value & OR $(95 \% \mathrm{Cl})$ & $P$ value & OR $(95 \% \mathrm{Cl})$ & $P$ value \\
\hline \multicolumn{7}{|c|}{ No. of cigarettes consumed ( $0-10$ as ref) } \\
\hline $11-20$ & & & & & $4.443(1.368-14.429)$ & 0.013 \\
\hline $21-30$ & & & & & $2.801(0.586-13.377)$ & 0.197 \\
\hline$\geq 31$ & & & & & $0.910(0.085-9.749)$ & 0.938 \\
\hline \multicolumn{7}{|c|}{ Time to first cigarette, $\min (\geq 61$ as ref) } \\
\hline $31-60$ & $2.706(0.670-10.935)$ & 0.162 & $2.693(0.608-11.936)$ & 0.192 & & \\
\hline $6-30$ & $3.954(1.170-13.364)$ & 0.027 & $4.916(1.343-17.991)$ & 0.016 & & \\
\hline$\leq 5$ & $9.788(2.761-34.695)$ & $<0.001$ & $9.871(2.604-37.424)$ & $<0.001$ & & \\
\hline \multicolumn{7}{|c|}{ Readiness for quitting ( $0-4$ as ref) } \\
\hline 5 & $10.301(3.330-31.864)$ & $<0.001$ & $7.807(2.545-23.954)$ & $<0.001$ & $2.27(0.657-7.836)$ & 0.195 \\
\hline $6-10$ & $12.603(4.931-32.215)$ & $<0.001$ & $12.155(4.686-31.530)$ & $<0.001$ & $6.519(2.466-17.234)$ & $<0.001$ \\
\hline \multicolumn{7}{|c|}{$\begin{array}{l}\text { Mean monthly income, HK\$ } \\
\text { (unemployed as ref) }\end{array}$} \\
\hline 1-9999 & $0.848(0.300-2.397)$ & 0.756 & $0.614(0.209-1.808)$ & 0.376 & & \\
\hline $10000-29999$ & $2.626(1.081-6.378)$ & 0.033 & $2.620(1.062-6.466)$ & 0.037 & & \\
\hline $30000-49999$ & $0.534(0.099-2.887)$ & 0.466 & $0.796(0.147-4.325)$ & 0.792 & & \\
\hline \multicolumn{7}{|c|}{ Financial intervention (no as ref) } \\
\hline Yes & $4.963(2.173-11.334)$ & $<0.001$ & 4.244 (1.838-9.799) & $<0.001$ & & \\
\hline
\end{tabular}

Abbreviations: $\mathrm{Cl}=$ confidence interval; $\mathrm{OR}=$ odds ratio; ref = reference; $\mathrm{SCCP}=$ Smoking Counselling and Cessation Programme

* Backward elimination procedure was applied; only results with at least one significant subcategory are shown

and may explain the differences in the baseline characteristics of participants in the two groups. Moreover, it is unknown whether there would be a difference in behaviour if free SCCP was offered from the beginning, instead of providing a fixedamount HK\$50 supermarket coupon that offered an extra HK\$5. Only the 7-day quit rate was used as the final programme outcome, as it was a standard outcome in the study centres. Future research with a robust randomisation process may be considered, as well as the use of longer abstinence periods such as 1 month, 3 months, and 12 months.

\section{Conclusion}

This study revealed that provision of a financial incentive that would indirectly cover the SCCP service fee might increase the proportion of smokers who agree to attend and make a booking to attend an SCCP. To reduce the barriers to accessing an SCCP service, budget holders should consider providing free and timely SCCP to motivated smokers. It is essential to catch smokers' moment of hesitation and to increase their access to the service.

\section{Supplementary information}

Online supplementary information (Appendices 1 and 2) is available for this article at www.hkmj.org.
TABLE 4. Waiting time for Smoking Counselling and Cessation Programme appointment and attendance rate

\begin{tabular}{lccc}
\hline & Total & Attended & $\begin{array}{c}\text { Rate (95\% confidence } \\
\text { interval) } \%\end{array}$ \\
\hline Same day as recruitment day & 7 & 7 & $100 \%(56.09 \%-100 \%)$ \\
Within 1 month & 13 & 9 & $69.23 \%(38.88 \%-89.64 \%)$ \\
$\geq 1$ Month & 38 & 14 & $36.84 \%(22.29 \%-54.00 \%)$ \\
Overall & 58 & 30 & $51.72 \%(38.34 \%-64.87 \%)$ \\
\hline
\end{tabular}

\section{Acknowledgements}

We thank the Hong Kong College of Family Physicians (HKCFP) for granting the HKCFP Trainee Research Fund 2015 for this study. We also thank the doctors and nurses in Cheung Sha Wan GOPC, Ha Kwai Chung GOPC, Li Po Chun GOPC, West Kowloon GOPC, South Kwai Chung GOPC, and Tsing Yi Cheung Hong GOPC for participant recruitment; Drs LS Chu, T Fong, KM Ho, and SY Tse for advice during research design; and Ms Ellen $\mathrm{Yu}$ and Mr Edward Choi for their support during the statistical analyses.

\section{Declaration}

The authors have no conflicts of interest to disclose. 


\section{References}

1. National Center for Chronic Disease Prevention and Health Promotion (US) Office on Smoking and Health. The Health Consequences of Smoking - 50 Years of Progress: a Report of the Surgeon General. 2014. Available from: http:// www.ncbi.nlm.nih.gov/pubmed/24455788. Accessed 6 Jun 2016.

2. Lam TH, Ho SY, Hedley AJ, et al. Mortality and smoking in Hong Kong: case-control study of all adult deaths in 1998. BMJ 2001;323:361.

3. McGhee SM, Ho LM, Lapsley HM, et al. Cost of tobaccorelated diseases, including passive smoking, in Hong Kong. Tob Control 2006;15:125-30.

4. Lam TH. Absolute risk of tobacco deaths: one in two smokers will be killed by smoking: comment on "Smoking and all-cause mortality in older people". Arch Intern Med 2012;172:845-6.

5. Simon JA, Carmody TP, Hudes ES, et al. Intensive smoking cessation counseling versus minimal counseling among hospitalized smokers treated with transdermal nicotine replacement: a randomized trial. Am J Med 2003;114:55562.

6. Ibrahim MI, N.A. Magzoub NA, Maarup N. Universitybased smoking cessation program through pharmacistphysician initiative: an economic evaluation. J Clin Diagn Res 2016;10:LC11-5.

7. Lancaster T, Stead LF. Individual behavioural counselling for smoking cessation. Cochrane Database Syst Rev 2005;(2)CD001292.

8. Cornuz J, Pinget C, Gilbert A, et al. Cost-effectiveness analysis of the first-line therapies for nicotine dependence. Eur J Clin Pharmacol 2003;59:201-6.

9. Wang D, Connock M, Barton P, et al. 'Cut down to quit' with nicotine replacement therapies in smoking cessation: a systematic review of effectiveness and economic analysis. Health Technol Assess 2008;12:iii-iv, ix-xi, 1-135.

10. Etter JF, Stapleton JA. Nicotine replacement therapy for long-term smoking cessation: a meta-analysis. Tob Control 2006;15:280-5.

11. Stead LF, Perera R, Bullen C, et al. Nicotine replacement therapy for smoking cessation. Cochrane Database Syst Rev 2012;(11):CD000146.

12. Stead LF, Koilpillai P, Fanshawe TR, et al. Combined pharmacotherapy and behavioural interventions for smoking cessation. Cochrane Database Syst Rev 2016(3):CD008286.

13. Hughes JR, Keely J, Naud S, et al. Shape of the relapse curve and long-term abstinence among untreated smokers. Addiction 2004;99:29-38.

14. Hong Kong Council on Smoking and Health. Smoking
Cessation Service Providers in Hong Kong. Available from: http://smokefree.hk/en/content/web.do?page=Services. Accessed 7 Jun 2015.

15. Census and Statistics Department, Government of the Hong Kong Special Administrative Region. Thematic Household Survey Report No. 59. Available from: http:// www.statistics.gov.hk/pub/B11302592016XXXXB0100. pdf. Accessed 1 Jul 2016.

16. Edwards SA, Bondy SJ, Callaghan RC, et al. Prevalence of unassisted quit attempts in population-based studies: a systemic review of the literature. Addict Behav 2014;39:5129.

17. Reda AA, Kotz D, Evers SM, et al. Healthcare financing systems for increasing the use of tobacco dependence treatment. Cochrane Database Syst Rev2012;(6):CD004305.

18. Dhalwani NN, Szatkowski L, Coleman T, et al. Nicotine replacement therapy in pregnancy and major congenital anomalies in offspring. Pediatrics 2015;135:859-67.

19. Borland R, Yong HH, O'Connor R, et al. The reliability and predictive validity of the Heaviness of Smoking Index and its two components: findings from the International Tobacco Control Four Country study. Nicotine Tob Res 2010;12 Suppl:S45-50.

20. Boudreaux ED, Sullivan A, Abar B, et al. Motivation rulers for smoking cessation: a prospective observational examination of construct and predictive validity. Addict Sci Clin Pract 2012;7:8.

21. Kaper J, Wagena EJ, Willemsen MC, et al. A randomized controlled trial to assess the effects of reimbursing the costs of smoking cessation therapy on sustained abstinence. Addiction 2006;101:1656-61.

22. Casagrande JT, Pike MC, Smith PG. An improved approximate formula for calculating sample sizes for comparing two binomial distributions. Biometrics 1978;34:483-6.

23. Sharp DJ, Hamilton W. Non-attendance at general practices and outpatient clinics: Local systems are needed to address local problems. BMJ 2001;323:1081-2.

24. Chan SC, Leung YP, Chan CH, et al. An Evaluative Study of the Integrated Smoking Cessation Services of Tung Wah Group of Hospitals. Tung Wah Group of Hospitals. 2011. Available from: http://icsc.tungwahcsd.org/file/evaluative_ study.pdf. Accessed 1 Jul 2016.

25. World Health Organization. WHO Report on the Global Tobacco Epidemic, 2015: Raising Taxes on Tobacco. Available from: http://apps.who.int/iris/ bitstream/10665/178574/1/9789240694606_eng.pdf? ua=12015. Accessed 1 Jul 2016.

26. Lang IA, Rice NE, Wallace RB, et al. Smoking cessation and transition into retirement: analyses from the English longitudinal study of ageing. Age Ageing 2007;36:638-43. 